University of Windsor

Scholarship at UWindsor

2014

\title{
Metamotivational tendencies, sociocultural attitudes, and risky eating behaviors
}

\author{
Ashlyne I. O'Neil \\ University of Windsor \\ Kathryn Lafreniere \\ University of Windsor
}

Follow this and additional works at: https://scholar.uwindsor.ca/psychologypub

Part of the Health Psychology Commons, and the Personality and Social Contexts Commons

\section{Recommended Citation}

O'Neil, Ashlyne I. and Lafreniere, Kathryn. (2014). Metamotivational tendencies, sociocultural attitudes, and risky eating behaviors. Journal of Motivation, Emotion, and Personality, 2 (1), 50-57.

https://scholar.uwindsor.ca/psychologypub/30

This Article is brought to you for free and open access by the Department of Psychology at Scholarship at UWindsor. It has been accepted for inclusion in Psychology Publications by an authorized administrator of Scholarship at UWindsor. For more information, please contact scholarship@uwindsor.ca. 


\title{
Metamotivational Tendencies, Sociocultural Attitudes, and Risky Eating Behaviors
}

\author{
Ashlyne I. O'Neil and Kathryn D. Lafreniere \\ University of Windsor
}

\begin{abstract}
Previous research has examined both sociocultural effects (e.g., Thompson et al., 2004) and personality influences (e.g., Cassin \& von Ranson, 2005) on eating disordered behavior. However, comparatively little research has employed the theoretical framework of reversal theory (RT). The present study examined the relationship between reversal theory's metamotivational personality constructs and risk of eating pathology, along with the mediating effects of sociocultural attitudes. A non-clinical sample of 123 undergraduate students completed the Motivational Style Profile (MSP), Sociocultural Attitudes Towards Appearance Questionnaire (SATAQ-3), Eating Attitudes Test (EAT-26), and a demographic profile. Simple t-tests suggested significant differences between males and females and the sexes were analyzed separately. The RT construct of autic sympathy (desire to be attractive and liked by others; Apter, Mallows \& Williams, 1998) was determined to be a significant predictor of increased eating pathology in the female subsample. This relationship was fully mediated by sociocultural factors. Rebelliousness was also significantly and positively related to risky eating behaviors. Findings are discussed in relation to the role of reversal theory in enhancing our understanding of risks associated with, and the ability to predict, the development of eating pathology. These results may contribute to the assessment and treatment of females who engage in risky eating behavior.
\end{abstract}

Keywords: eating disorders; sociocultural attitudes; metamotivational constructs; autic sympathy

The issue of eating disorders has gained prominence in developed societies worldwide. With the increased availability of fast food and other unhealthy options, much attention has been drawn to the rising obesity rates; in Canada, $24.1 \%$ of adults over the age of 18 , and $8 \%$ of children aged 2-18 years are classified as obese (Shields, Carroll, \& Ogden, 2011; Statistics Canada, 2009). In the United States, the statistics are even more alarming, with $35.7 \%$ of adults and $16.9 \%$ of children classified as obese (Ogden, Carroll, Kit, \& Flegel, 2012). But while these rates escalate, the media continues to portray exceptionally thin or "fit" people (especially females) as the norm. This gives the increasingly overweight population a skewed representation of reality, leading many to seek achievement of the same body type. In the U.S. $2.7 \%$ of children aged $13-18$ and $0.6 \%$ of adults are diagnosed with eating disorders (Hudson, Hiripi, Pope, \& Kessler, 2007; Merikangas, et al., 2010). Further, a Canadian study conducted in the Maritimes suggested that $7.7 \%$ of girls aged 11-15 displayed

Correspondence concerning this article should be addressed to Kathryn D. Lafreniere, Psychology Department, University of Windsor, 401 Sunset Ave., Windsor, ON, N9B 3P4, Canada. E-mail: lafren1@uwindsor.ca a high risk for developing an eating disorder (Gusella, Goodwin, \& van Roosmalen, 2008).

The Diagnostic and Statistical Manual for Mental Disorders (DSM-V, American Psychiatric Association, 2013) describes eating disorders as a severe disturbance in eating behavior, listing three conditions, Anorexia Nervosa, Bulimia Nervosa, and Binge Eating Disorder as the main eating disorders. Anorexia is characterized by an intense fear of gaining weight, distorted perception of body shape and weight, and a body weight under $85 \%$ of what is considered normal for one's specific age and height (American Psychiatric Association, 2013). Bulimia is characterized by bingeing (i.e. eating significantly more than a normal person would in a given time) and purging (i.e. engaging in inappropriate compensatory strategies to prevent weight gain) behaviors, which must both occur at least once a week for three months or more (American Psychiatric Association, 2013). For the purpose of the current study, diagnosed eating disorders were not examined; rather, the risky eating behaviors that can lead to such diagnoses were explored. These have been defined in the realm of oral control, dieting, and bulimia. According to Garner, Olmsted, Bohr, and Garfinkel (1982), oral control refers to the individual's ability to control food intake, along with the pressure they perceive from other people concerning their weight. Dieting is described as the "avoidance of fatten- 
ing foods and preoccupation with being thinner" (Garner et al., 1982, p. 873). Finally, bulimia refers to binge and purge behaviors, as well as the presence of abundant thoughts about food.

There is a commonly shared idea that the media holds at least some responsibility for the development of such eating behaviors, especially in adolescents (Thompson \& Heinberg, 1999). The fact that the fashion industry displays an obsession with extremely thin female models presents many girls with an unrealistic ideal body image. Young women often attempt to achieve this ideal by engaging in unhealthy eating and compensatory behaviors (Kerr, Lindner, \& Blaydon, 2007). But why is it that some individuals are more affected by these messages than others? Thompson, van den Berg, Roehrig, Guarda, and Heinberg (2004) have outlined three major sociocultural factors that affect the development of eating pathology. Internalization is "the extent to which an individual cognitively buys into societal norms of size and appearance" (Thompson \& Stice, 2001, p. 181) to the point where one modifies his or her behavior to fit these ideals. General internalization reflects the overall influence of the media, whereas athletic internalization more specifically reflects the internalization of athletic and sports figures. The pressures construct refers to the perception of media as a pressure, such that people feel direct pressure from media to fit a specific body type. The final construct, information, reflects the perception of media as an informational source, and evaluates the extent to which people believe different facets of the media to be an important source of information on attractiveness (Thompson et al., 2004). Though the effects of such media influences have been studied, how they mediate the relationship with motivational personality profiles and eating pathology has not.

The abundance of research in the field of eating disorders has aimed to identify risk factors for eating disorders such as low self-esteem, negative comments targeted at appearance, modeling of disturbed eating patterns, and the physical ideals presented by the media (Thompson et al., 2004). In a meta-analysis that examined personality disorders in relation to eating disorders, Cassin and von Ranson (2005) found that both Anorexia and Bulimia Nervosa tended to be related to perfectionism, neuroticism, obsessive-compulsiveness, negative emotionality, low self-directedness, and low cooperativeness. To date, there has been relatively little research examining reversal theory constructs and their relation to eating behavior patterns. The metamotivational states proposed by reversal theory may make further conceptual contributions to the field of eating disorders, in that it emphasizes the changeability in people and can help explain why individuals may engage in behaviors such as restrictive dieting, bingeing, and purging regardless of the health risks. Therefore it is of significant interest to establish and support an explanation of disordered eating using a reversal theory perspective. We propose that recognizing the relationship between metamotivational personality tendencies and problematic eating behaviors could have therapeutic and preventative implications.

Reversal theory (RT) is a theory of motivation, emotion, and personality that acknowledges the necessary inconsistencies of human nature (Apter, 2001). RT is based on four main pairs of opposite and mutually exclusive metamotivational states that we reverse between in our daily lives. These states represent how people experience their world according to their primary needs and goals, and reversals are triggered by events such as environmental stimuli, frustration (not attaining a goal or fulfilling one's current emotional needs), or satiation (Apter, 2007). The pairs are made up of telic-paratelic (goal oriented versus living in the moment), conformist-negativistic (compliant versus rebellious), mastery-sympathy (controlling versus agreeable), and auticalloic (self, versus other centered). The last two pairs can also be combined to form states such as autic mastery (seeking control over an aspect of oneself) and autic sympathy (seeking affection from others).

When an individual has a greater tendency to experience a specific state over time, they display dominance within that pair of motivational states. For example, a person who is telic dominant would spend more time working to achieve goals than relaxing or living in the moment. Despite people's tendencies toward motivational dominance, RT maintains that psychological health is attained and preserved when one undergoes regular reversals between these states, and that psychopathology is rooted in the inhibition or over-facilitation of reversals (Lafreniere, Ledgerwood, \& Murgatroyd, 2001).

There is currently a limited amount of literature documenting the relationship between RT constructs and eating pathology. A study conducted by Blaydon, Lindner, and Kerr (2004) compared four groups of individuals who were either healthy controls, exercise dependent, eating disordered, or exercise dependent and eating disordered. They demonstrated that both eating disordered groups displayed higher levels of telic and conformist dominance, while those in the eating disorder only group displayed higher sympathy, compared to the exercise dependent and control groups. The authors suggested that the relationship between eating disordered groups and telic dominance likely reflects inappropriate or inhibited reversals, creating obsessional characteristics. These obsessive characteristics are said to occur when the telic state is either being over-facilitated by, or inhibited from reversals to the paratelic mode, which prompts the individual to use strategies (e.g., exercise, diet, or purging) to achieve satisfaction and reduce anxiety (Blaydon et al., 2004).

In research on weight-cyclers, Popkess-Vawter, Wendel, Schmoll, and O'Connell (1998) found that these individuals often reported specific emotional triggers that provoked them to engage in overeating. Specifically, they found that normal- 
weight subjects tended to view overeating as a positive experience and were more often in the sympathy state when engaging in overeating, but in the telic and mastery states when resisting overeating. However, while weight-cyclers tended to be in the telic state (except during the overeating event), they appeared to reverse between mastery and sympathy throughout the process of experiencing the temptation, deciding whether or not to overeat, overeating, and their feelings afterwards. The authors suggested that by understanding the reasoning behind human inconsistencies (described by RT), people would learn to "recognize, accept, and develop new skills to deal with their naturally occurring positive and negative motivations" (Popkess-Vawter et al., 1998, p. 82). This may also lead them to identify the emotional triggers leading to their reversal and subsequent overeating behaviors. These proposals may be expanded to suggest the use of RT to identify emotional triggers that lead to risky eating behaviors as identified in this study.

The purpose of the present study was to examine how RT can aid in the recognition of attitudes and behavioral tendencies that may lead to the development of eating disorders. Self-report measures of motivational dominance, sociocultural attitudes toward appearance, and eating pathology were administered to a sample of undergraduate university students in order to examine how metamotivational tendencies and societal influence might be associated with risky eating patterns.

We hypothesized that telic dominance would be positively correlated with risky eating behaviors. Because individuals who display eating pathology are likely attempting to achieve acceptance (i.e. they think that they will be more attractive and loved if they have a smaller or fit figure), we also predicted that eating pathology would be positively associated with autic sympathy dominance. In addition, we explored the relationships between the RT constructs of negativism/conformity dominance and eating pathology, and examined whether sociocultural attitudes mediated the relationships between the RT constructs and risky eating behaviors.

\section{Method}

\section{Participants}

In total, 123 undergraduate student participants (79 females, 42 males, and 2 unknown) who ranged in age from 17 to 27 years $(M=20.41)$ were recruited through the Psychology Department Participant Pool from the University of Windsor, Canada. While the majority identified themselves as Caucasian (57\%), the sample also included Asian (19\%), African/Caribbean (12\%), and a variety of other ethnicities (12\%). All participants received bonus credit toward an eligible psychology course.

\section{Procedure and Measures}

Institutional ethics approval was attained prior to the commencement of data collection. Once informed consent was obtained, participants completed the questionnaires in small groups in a seminar room. Upon completion, participants were given feedback about the study and a list of helpful community resources. The entire process took 20-30 minutes and each participant was rewarded with half a bonus credit towards an eligible psychology course.

The questionnaire consisted of the following measures:

Motivational Style Profile. The MSP (Apter, Mallows, \& Williams, 1998) is a 70-item measure of RT metamotivational personality tendencies that was scored on a six-point Likert scale (Apter, 2007). Eight subscales measure metamotivational dominance in each of the RT states (i.e. telic/paratelic, negativism/conformity, mastery/sympathy and autic/alloic). Dominance scores are derived by subtracting each state score from its opposite (i.e. subtracting conformity from negativism to obtain negativism dominance). In the present study, only the telic dominance, negativism, and autic sympathy subscales were used. Internal consistency of these subscales was found to be adequate, ranging from .69 to .78 (see Table 1).

Sociocultural Attitudes Towards Appearance Scale-3. (SATAQ-3; Thompson et al. 2004).This 30-item questionnaire, scored on a five-point Likert scale, assesses sociocultural attitudes related to appearance and internalization of the thin ideal that have been found to be associated with the development of eating disordered behavior. The subscales of General Internalization ( $\alpha=.96)$, Athletic Internalization ( $\alpha=.95)$, Information ( $\alpha=.96)$, Pressures $(\alpha=.92)$, as well as a total score $(\alpha=.96)$ have shown strong internal consistency (Thompson et al., 2004) which was also supported in the present sample.

Eating Attitudes Test-26. The EAT-26 (Garner et al., 1982) consists of 26 questions measured on a six-point Likert scale, and is a revised version of the earlier EAT-40 (Garner \& Garfinkel, 1979). This measure contains Dieting, Bulimia, and Oral Control subscales, which aim to identify possible risk behaviors associated with eating disorders. This measure is commonly used as a sub-clinical measure by which people with a total score of 20 or above are referred to a diagnostic interview and directed to seek professional advice. When using this approach, the first three points on the Likert scale are scored as zero for the first 25 questions, and the last three points are coded as zero for the final question. In this way, individuals who respond frequently with "often", "usually", or "always" for multiple items are flagged as potential clinical cases. However, while this clinical cut-off score was briefly examined, the EAT-26 was scored as a continuous measure for the purpose of correlational analyses in the present study. Internal consistency reliability for the total scale and subscales is shown in Table 1. 
Table 1

Means, Standard Deviations, and Reliabilities for Scales and Subscales

\begin{tabular}{lcccccc}
\hline Scale & Possible & Actual & $n$ & $M$ & $S D$ & $\alpha$ \\
\hline MSP & & & & & & \\
$\quad$ Autic-Sympathy & $5.0-30.0$ & $11.0-29.0$ & 123 & 20.05 & 4.03 & .71 \\
$\quad$ Negativism & $5.0-30.0$ & $5.0-26.0$ & 121 & 13.25 & 4.09 & .78 \\
$\quad$ Telic Dominance & $-25.0-25.0$ & $-11.0-11.00$ & 123 & 1.61 & 4.38 & .69 \\
SATAQ-3 & & & & & & \\
$\quad$ Internalization General & $9.0-45.0$ & $9.0-45.0$ & 122 & 25.52 & 9.11 & .92 \\
$\quad$ Internalization Athlete & $5.0-25.0$ & $5.0-25.0$ & 122 & 15.29 & 5.03 & .85 \\
$\quad$ Pressures & $7.0-35.0$ & $7.0-35.0$ & 122 & 18.52 & 7.71 & .92 \\
$\quad$ Information & $9.0-45.0$ & $9.0-45.0$ & 121 & 25.50 & 9.09 & .92 \\
EAT-26 & & & & & & \\
$\quad$ Dieting & $13.0-78.0$ & $13.0-73.0$ & 121 & 32.03 & 13.65 & .92 \\
$\quad$ Bulimia & $6.0-36.0$ & $6.0-36.0$ & 123 & 10.90 & 4.67 & .82 \\
$\quad$ Oral Control & $6.0-36.0$ & $6.0-36.0$ & 123 & 13.18 & 4.35 & .59 \\
$\quad$ EAT-Total & $26.0-156.0$ & $29.0-151.0$ & 121 & 58.44 & 19.78 & .92 \\
\hline
\end{tabular}

Table 2

Correlations between Reversal Theory Constructs, Mediating and Outcome Variables

\begin{tabular}{|c|c|c|c|c|c|c|c|c|c|c|c|c|}
\hline & GI & $\mathrm{AI}$ & I & $\mathrm{P}$ & $\mathrm{D}$ & B & $\mathrm{OC}$ & EAT & AM & AS & $\mathrm{N}$ & $\mathrm{TD}$ \\
\hline \multicolumn{13}{|l|}{ SATAQ-3 } \\
\hline General Internalization & - & & & & $.70 * *$ & $.54 * *$ & $.30 * *$ & $.66 * *$ & $-.41 * *$ & $.47 * *$ & .08 & -.08 \\
\hline Athletic Internalization & & - & & & $.58 * *$ & $.40 * *$ & $.23 *$ & $.53 * *$ & -.14 & .14 & .01 & .11 \\
\hline Information & & & - & & $.37 * *$ & $.40 * *$ & $.42 * *$ & $.44 * *$ & -.18 & $.28^{*}$ & .01 & -.13 \\
\hline Pressures & & & & - & $.70 * *$ & $.57 * *$ & $.27 *$ & $.66^{* *}$ & $-.42 * *$ & $.42 * *$ & .11 & -.06 \\
\hline \multicolumn{13}{|l|}{ EAT-26 } \\
\hline Dieting & .27 & $.42 * *$ & .30 & $.55 * *$ & - & & & & $-.34 * *$ & $.41 * *$ & .21 & -.04 \\
\hline Bulimia & .04 & .16 & .24 & $.43 * *$ & & - & & & $-.33^{* *}$ & $.39 * *$ & $.41 * *$ & $-.24 *$ \\
\hline Oral Control & .02 & -.01 & .12 & .07 & & & - & & -16 & $.27 *$ & $.32 * *$ & -.06 \\
\hline EAT-total & .20 & $.35^{*}$ & $.34 *$ & $.54 * *$ & & & & - & $-.34 * *$ & $.42 * *$ & $.32 * *$ & -.11 \\
\hline \multicolumn{13}{|l|}{ RT Constructs } \\
\hline Autic-Mastery & -.17 & -.01 & -.24 & -.20 & -.17 & -.05 & -.07 & -.17 & - & & & \\
\hline Autic-Sympathy & .29 & .24 & .24 & .28 & .13 & .01 & -.01 & .10 & & - & & \\
\hline Negativism & -.09 & .12 & .11 & -.03 & .07 & .13 & -.08 & .07 & & & - & \\
\hline Telic & .22 & .16 & -.26 & .21 & .24 & -.10 & .11 & .17 & & & & - \\
\hline
\end{tabular}

Note. two tailed significance tests, ${ }^{*} p<.05$, $* * p<.01$, above diagonal represents females, below diagonal represents males

Demographic Information. Participants were also asked about their age, sex, ethnicity, education, and whether they had a current eating disorder diagnosis ("Are you currently diagnosed with an eating disorder?").

\section{Results}

\section{Preliminary Data Analysis Considerations}

Simple t-tests revealed significant differences between males and females on most variables of interest $(p<.05)$, with the exception of information, oral control, and telic dominance, in which there were no significant sex differences. Over all, females scored higher on general internalization, pressures, dieting, bulimia, EAT-total, and auticsympathy, while males scored higher on athletic internaliza- tion, negativism, and autic-mastery. In light of these differences, the sexes were analyzed separately. Correlations were then examined among all variables to determine which variables should be included in the subsequent regression analyses. Standard regression analyses, in which all of the predictors are simultaneously added to the regression equation, and Baron and Kenny's (1986) mediation tests were conducted in the female subsample, with EAT-26 subscales as dependent variables. Due to the small size of the male subsample, only correlational analyses were conducted for the males.

Internal consistency of all scales and subscales was assessed using Cronbach's alpha, and all measures were found to show adequate internal consistency. The means, standard deviations, and reliabilities of these variables can be seen in Table 1. 
Table 3

Regression Analyses for Autic Sympathy and Sociocultural Variables Predicting Eating Pathology

\begin{tabular}{llllll}
\hline Outcome Variable & Predictor Variable & $\beta$ & $t$ & $s r^{2}$ & $R^{2}$ \\
\hline Dieting & Autic-Sympathy & .13 & 1.40 & .01 & .51 \\
& Pressures & .65 & $7.20^{* * *}$ & .34 & \\
& Autic-Sympathy & .11 & 1.25 & .01 & .50 \\
& General Internalization & .65 & $7.12^{* * *}$ & .34 & \\
& Autic-Sympathy & .18 & 1.82 & .03 & .36 \\
Bulimia & Pressures & .50 & $4.89^{* * *}$ & .20 & \\
& Autic-Sympathy & .17 & 1.61 & .02 & .32 \\
& General Internalization & .46 & $4.30^{* * *}$ & .17 & \\
& Autic-Sympathy & .17 & 1.59 & .03 & .21 \\
Oral Control & Information & .38 & $3.53^{* *}$ & .13 & \\
& Autic-Sympathy & .16 & 1.65 & .02 & .46 \\
EAT-total & General Internalization & .59 & $6.27^{* * *}$ & .28 & \\
\hline
\end{tabular}

Note. $* * p<.01 * * * p<.001$

\section{Correlational and Mediation Tests}

To test the possible mediating effect of the SATAQ subscales on the relationship between the EAT subscales and the RT constructs, Baron and Kenny's (1986) procedure was used. ${ }^{1}$ In the female subsample, telic dominance was negatively related to bulimia, while negativism was positively correlated with bulimia, oral control, and EAT-total. Further, autic sympathy was significantly and positively related to all aspects of females' eating pathology. This relationship was mediated by the sociocultural variables: general internalization, pressures, and information. Correlations among these constructs are shown in Table 2.

In the present study, autic sympathy was significantly correlated with information. Autic sympathy was also significantly correlated with oral control. In a standard regression that examined the effects of information and autic sympathy on oral control, information was the only significant predictor of oral control, $(\beta=0.38, p<.01)$, while the effect of autic sympathy was not significant. Thus, according to Baron and Kenny's method, information mediated the relation between autic sympathy and oral control. A summary of regression findings can be found in Table 3.

Autic sympathy was significantly correlated with both general internalization and bulimia. A standard regression then examined the effects of general internalization and autic-sympathy on bulimia and determined that general internalization was the only significant predictor of bulimia $(\beta=0.46, p<.001)$, while the effect of autic sympathy be- came non-significant. Thus, general internalization mediated the relation between autic-sympathy and bulimia.

Autic sympathy was significantly correlated with general internalization and dieting. Through conducting another standard regression, it was established that general internalization was the only significant predictor of dieting, ( $\beta=0.65, p<.001$ ), while the effect of autic sympathy on dieting was not significant. Thus, general internalization mediated the relation between autic sympathy and dieting.

General internalization was also shown to have a significant mediating effect on the relationship between autic sympathy and the total EAT score (indication of eating pathology). Autic sympathy was correlated with both general internalization and with total scores on the EAT. A standard regression determined that general internalization was the only significant predictor of the total EAT score $(\beta=0.59, p<$ .001 ), while the effect of autic sympathy on EAT-total was not significant, indicating full mediation.

Autic sympathy was found to be significantly correlated with both sociocultural pressures and bulimia. A standard regression showed that pressures was the only significant pre-

\footnotetext{
${ }^{1}$ According to Baron and Kenny (1986), a mediation effect occurs when the following happens: (1) the independent variable is significantly related to the mediator, (2) the independent variable is significantly related to the dependent variable, (3) the mediator is significantly related to the dependent variable when the dependent variable is regressed on the independent variable and the mediator, and (4) the relation between the independent variable and the dependent variable becomes nonsignificant when the mediator is added to the regression model.
} 
dictor of bulimia $(\beta=.50, p<.001)$ while the effect of autic sympathy was not significant. This also indicates a full mediating effect of pressures on the relation between autic sympathy and bulimia.

Finally, it was determined that sociocultural pressures also fully mediated the relation between autic sympathy and dieting. Autic sympathy was significantly correlated with both pressures and dieting. A standard regression was then performed to examine the effects of pressures and autic sympathy on dieting, and found that pressures was the only significant predictor of dieting, $(\beta=0.65, p<.001)$.

In summary then, sociocultural pressures and general internalization both mediated the effect of autic sympathy on dieting. Pressures and general internalization also mediated the effects of autic sympathy on bulimia. Information acted as a mediator in the relationship between autic sympathy and oral control, and general internalization was a full mediator in the relationship between autic sympathy and total EAT score.

\section{Findings from the Male Subsample}

Males showed no significant correlations between RT constructs and any of the mediating or outcome variables, as can be seen in Table 2. However, athletic internalization was found to be significantly correlated with dieting, and with the total EAT score. Pressures was significantly correlated with dieting, bulimia, and EAT-total in the male subsample.

\section{Discussion}

Our results suggest that females who report higher levels of autic sympathy (the desire to be attractive, loved and accepted) experience increased eating behaviors related to dieting and bulimia, and higher levels of oral control and overall eating pathology. These relationships were mediated by sociocultural attitudes, implying that higher levels of autic sympathy may put females at a greater risk of eating pathology through internalizing cultural messages as well as increasing their perception of pressure and information from these messages.

The negative correlation between telic dominance and bulimia (in females) may be explained by the binge-eating symptom of bulimia, which might be more likely to occur in the paratelic state in which an individual "lives in the moment" and has less concern for future consequences. Further research in this field could seek to substantiate this claim, and possibly examine the state reversals that occur when an individual is bingeing and purging, to help identify what triggers their reversals and subsequent behavior.

Finally, the relationship between negativism and higher levels of bulimia, oral control, and overall eating pathology suggests that these individuals typically enjoy acting against societal norms. Further, because dieting is typically more acceptable than binge-purge behavior, those who score higher on bulimia may be doing so to act against the societal norms of dieting and weight management.

The males in our study displayed no significant relationships between the metamotivational personality constructs and eating pathology. While sociocultural pressures and general internalization mediated relationships between autic sympathy and eating pathology in women, men showed a greater relationship between athletic internalization and risky eating. These findings suggest that while men and women both perceive messages in the media as a source of pressure, how they internalize those messages is different. Zellner, Harner, and Adler (1989) found that while females often strive to be thinner than they think they are - even thinner than what they think men find attractive - men are typically satisfied with their bodies. This consideration may have contributed to the sex differences found in our study, in that men may not show a great variation in their eating patterns, regardless of their metamotivational profile. However, Warren (2008) discovered that males do experience body dissatisfaction, and that it tends to be related to the awareness and internalization of western male appearance ideals, which are represented by broad shoulders, muscularity, and fitness (such as super heroes and male models).

Findings from this study have implications for both therapy and prevention of eating disorders in females. By recognizing one's motivational personality tendencies, an individual may be able to identify triggers that induce reversals that lead to disordered eating behaviors. Likewise, if a woman is able to acknowledge her heightened desire for acceptance and affection (a pattern associated with autic sympathy dominance) and that she may be more susceptible to media and cultural pressures to be thin, it may provide a helpful foundation for therapeutic change. As suggested by Popkess-Vawter et al. (1998), people can learn to recognize, accept, and develop coping skills to deal with their natural inconsistencies (i.e. arising from their dominant metamotivational states). If, by focusing on decreasing the overwhelming desire to be attractive, admired and accepted by others, one can decrease her likelihood of internalizing sociocultural messages and pressures, then administering a measure of autic sympathy could be a primary step in the assessment of someone who is susceptible to disordered eating behaviors.

A primary limitation of the current study is that the sample was small, and the need to subdivide the sample by sex resulted in a subsample of 79 women on which to conduct the main analyses, and a subsample of 42 men that precluded conducting multivariate analyses on the males. The use of a university sample also limited diversity in terms of age, ethnicity, and educational attainment. Another limitation regarding the sample is that the average age was just over 20 years old. Because eating disorders often peak in adolescence, using a younger sample might have elicited different results. 
Further research should be conducted on the relationship between metamotivational constructs, sociocultural attitudes, and eating pathology using a larger, younger sample of female adolescents. Because eating disorders are most prevalent in the teenage years (American Psychiatric Association, 2000) it is crucial to identify risky eating behaviors before the individual develops a disorder, which would subsequently be more difficult to treat.

Research that focuses on specific metamotivational state reversals, their triggers, and the subsequent influence on eating behaviors would be optimal and could be accomplished by asking participants to keep a journal, or complete weekly self-report measures to determine what leads people to engage in risky eating behaviors. Since autic sympathy was the most salient predictor of susceptibility to sociocultural influences and eating pathology, interventions that focus on deconstructing young women's connection between the need to be attractive, loved, and accepted and their appearance concerns should be developed and evaluated in samples of adolescent women.

In conclusion, findings from the present study suggest that RT can act as a functional theoretical framework for the identification of psychological characteristics that increase susceptibility to pathological eating behaviors. The identification of autic sympathy as an important intra-individual construct that operates through sociocultural attitudes to influence eating pathology suggests that RT could be useful in developing treatment plans for young women who are susceptible to eating pathology.

\section{References}

American Psychiatric Association. (2013). Diagnostic and statistical manual of mental disorders (5th ed.). Washington, DC: American Psychiatric Association.

Apter, M. J. (2001). Motivational styles in everyday life: A guide to reversal theory. Washington, DC: American Psychological Association.

Apter, M. J. (2007). Reversal theory: The dynamics of motivation, emotion and personality (2nd ed). Oxford, England: Oneworld Publications.

Apter, M. J., Mallows, R., \& Williams, S. (1998). The development of the Motivational Style Profile. Personality and Individual Differences, 24(1), 7-18. http://dx.doi.org/10.1016/S0191-8869(97)00148-7

Baron, R.M., \& Kenny, D.A. (1986). The moderatormediator variable distinction in social psychological research: Conceptual, strategic, and statistical considerations. Journal of Personality and Social Psychology, 51, 1173-1182. http://dx.doi.org/10.1037/00223514.51.6.1173

Blaydon, M. J., Lindner, K. J., \& Kerr, J. H. (2004). Metamotivational characteristics of exercise dependence and eating disorders in highly active amateur sport participants.
Personality and Individual Differences, 36, 1419-1432. http://dx.doi.org/10.1016/S0191-8869(03)00238-1

Cassin, S. E., \& von Ranson, K. M. (2005). Personality and eating disorders: A decade in review. Clinical Psychology Review, 25(7), 895-916. http://dx.doi.org/10.1016/j.cpr.2005.04.012

Garner, D.M., \& Garfinkel, P.E. (1979). The eating attitudes test: An index of the symptoms of anorexia nervosa. Psychological Medicine, 9, 273-279. http://dx.doi.org/10.1017/S0033291700030762

Garner, D., Olmsted, M., Bohr, Y., \& Garfinkel, P. (1982). The eating attitudes test: Psychometric features and clinical correlates. Psychological Medicine, 12(4), 871-878. http://dx.doi.org/10.1017/S0033291700049163

Gusella, J., Goodwin, J., \& van Roosmalen, E. (2008). 'I want to lose weight': Early risk for disordered eating? Paediatric Child Health, 13(2), 105-110.

Hudson, J.I., Hiripi, E., Pope, H.G., \& Kessler, R.C. (2007). The prevalence and correlates of eating disorders in the national comorbidity survey replication. Biological Psychiatry, 61, 348-358. http://dx.doi.org/10.1016/j.biopsych.2006.03.040

Kerr, J., Lindner, K., \& Blaydon, M. (2007). Exercise dependence. New York, NY: Routledge.

Lafreniere, K. D., Ledgerwood, D. M., \& Murgatroyd, S.J. (2001). Psychopathology, therapy, and counseling. In M.J. Apter (Ed.), Motivational styles in everyday life: A guide to reversal theory (pp. 263-285). Washington, DC: American Psychological Association.

Merikangas, K.R., He, J., Burstein, M., Swanson, S.A., Avenevoli, S., Cui, L., Benjet, C., Georgiades, K., \& Swendsen, J. (2010). Lifetime prevalence of mental disorders in U.S. adolescents: Results from the national comorbidity study- adolescent supplement. Journal of the American Academy for Child and Adolscent Psychiatry, 49(10), 980-989. http://dx.doi.org/10.1016/j.jaac.2010.05.017

Ogden, C., Carroll, M., Kit, B., \& Flegel, K. (2012). Prevalance of obesity in the United State 2009-2010. NCHS Data Brief, 82. Hyattsville, MD: National Center for Health Statistics.

Popkess-Vawter, S., Wendel, S., Schmoll, S., \& O'Connell, K. (1998). Overeating, reversal theory, and weight cycling. Western Journal of Nursing Research, 20(1), 67-83. http://dx.doi.org/10.1177/019394599802000105

Shields, M., Carroll, M. D., \& Ogden, C. L. (2011). Adult obesity prevalence in Canada and the United States. National Center for Health Statistics Data Brief, 56. Retrieved from: http://www.cdc.gov/nchs/data/ databriefs/db56.pdf.

Statistics Canada. (2009). Overweight Canadian children and adolescents. Retreived from: http://www. statcan.gc.ca/pub/82-620-m/2005001/article/child-enfant/ 8061-eng.htm. 
Thompson, J., \& Heinberg, L.J. (1999). The media's influence on body image disturbance and eating disorders: We've reviled them, now can we rehabilitate them? Journal of Social Issues, 55(2), 339-353.

Thompson, J., \& Stice, E. (2001). Thin-ideal internalization: Mounting evidence for a new risk factor for image disturbance and eating pathology. Current Directions in Psychological Science, 10(5), 181-183. http://dx.doi.org/10.1111/1467-8721.00144

Thompson, J., van den Berg, P., Roehrig, M., Guarda, A. \& Heinberg, L. (2004). The Sociocultural Attitudes Towards Appearance Questionnaire-3 (SATAQ-3): Develop- ment and validation. International Journal of Eating Disorders, 35, 293-304. http://dx.doi.org/10.1002/eat.10257

Warren, C.S. (2008). The influence of awareness and internalization of western appearance ideals on body dissatisfaction in Euro-American and Hispanic males. Psychology of Men and Masculinity, 9(4), 257-266. http://dx.doi.org/10.1037/a0012472

Zellner, D., Harner, D., \& Adler, R. (1989). Effects of eating abnormalities and gender on perception of desirable body shape. Journal of Abnormal Psychology, 98(1), 9396. http://dx.doi.org/10.1037/0021-843X.98.1.93 